\title{
Sverdrup, Johnson, and Fleming's The Oceans Revisited: What of the Future of Graduate Education in Ocean Sciences?
}

\author{
John W. Farrington \\ Woods Hole Occanographic Institution - Woods Hole, Massachusetts USA
}

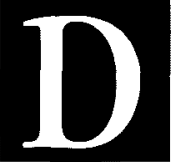

James Baker, in his introduction to a series of articles celebrating the 50th anniversary of the book The Oceuns (Sverdrup, Johnson, and Fleming, 1942), tells a story about starting in oceanography as a summer fellow at Scripps Institution of Oceanography (SIO) on an expedition with John Knauss. "John told me that if I wanted to be an oceanographer, then I had to read The Oceans as a start." (Baker, 1992).

Sverdrup, Johnson and Fleming's venerable 1942 book, The Oceans, provided an excellent text into the 1950 s for graduate education in oceans sciences and was recommend reading when I began my graduate education in oceanography in the fall of 1968 at the Graduate School of Oceanography (GSO), University of Rhode Island (URI). The opening paragraph of The Oceans states:

Oceanography embraces all studies pertaining to the sea and integrates the knowledge gained in the marine sciences that deal with such subjects as the ocean boundaries and bottom topography, the physics and chemistry of sea water, the types of currents, and the many phases of marine biology. The close interrelation and mutual dependence of the single marine sciences have long been recognized.

Reading this paragraph a year ago, during a period of contemplation about the present and future curriculum in the MIT/WHOI Joint Program in Oceanography and Applied Ocean Sciences and Engineering, stimulated my thinking about graduate education in ocean sciences over the past several decades.
During the 1960s, recognition of the increasing importance of the oceans to humanity led in the USA to the Stratton Commission report "Our Nation and the Sea," and the founding of Sea Grant. On the world scene, the 1970s International Decade of Ocean Exploration was launched. In parallel there was a significant expansion of graduate education programs in oceanography and marine sciences in the United States. One of the universities participating in this expansion in the 1960s was the University of Rhode Island with the transformation of the URI Narragansett Marine Laboratory into the Graduate School of Oceanography (GSO) under the leadership of the first Dean of the $\mathrm{GSO}$, John Knauss. Expansions in faculty and graduate student enrollment occurred at URI-GSO and most of the other larger ocean sciences graduate research and education universities - usually referred to as the Joint Oceanographic Institution (JOI) schools-Universities of Washington, Hawaii, Texas, Miami, Rhode Island; Oregon State University, Texas A \& M University, Scripps Institution of Oceanography (University of California-San Diego), Lamont Doherty Geological Observatory (now Earth Observatory) of Columbia University, and Woods Hole Oceanographic Institution.

The main intent of graduate education for the Ph.D. during these times of the 1960s and 1970s was focused on education and training to provide for the expansion

This articte is an expansion of a paper presented at the 75 th birthday celdbration for lolm Kulauss at the Graduate School of Oceanograply, Lniversity of Rhode Island and a later abstract for a poster at the American Geophysical Union meting, December 2000 . 
of oceans sciences faculty at JOI schools but also at many colleges and universities that, like URI of the 1950s and early 1960s, had mainly a marine coastal laboratory with a focus on marine biological research. GSO-URI, under John Knauss' leadership as Dean, began graduating M.S. and Ph.D. students to meet this goal (Figure 1). This general pattern of a rapid increase in degrees granted and then a general leveling off around the late 1970s to early 1980s was repeated at most, if not all, JOI schools (Nowell and Hollister, 1988).

What was the influence of John Knauss on graduate education at GSO? In a recent Maritimes article, Admiral James Watkins, United States Navy (Retired), President of the Consortium for Oceanographic Research and Education, noted that John Knauss resisted the trend to organize formal departments representing the subdisciplines of ocean sciences or oceanography and "encouraged researchers to collaborate and integrate their research". The result is certainly in accord with the Sverdrup, Johnson and Fleming quote above. This is not surprising since, as noted elsewhere in this volume, Sverdrup at Scripps Institution of Oceanography had a strong influence on John Knauss while John was a graduate student at SIO.

\section{Breadth and depth in graduate education in oceanography}

During John Knauss' tenure as Dean of GSO, a required part of the program of graduate study was completing all four core courses; physical, chemical, biological and geological oceanography. John Knauss taught the core course in physical oceanography when I was a graduate student. Since my graduate education days at GSO, I have been thankful for that introduction to those four facets of oceanography; an introduction that mixed both breadth and depth of knowledge of the oceans, the underlying sediments, and the ocean basins. The debates about a curriculum for graduate study for oceanography or ocean sciences today are often most heated when discussing the pros and cons of "the four

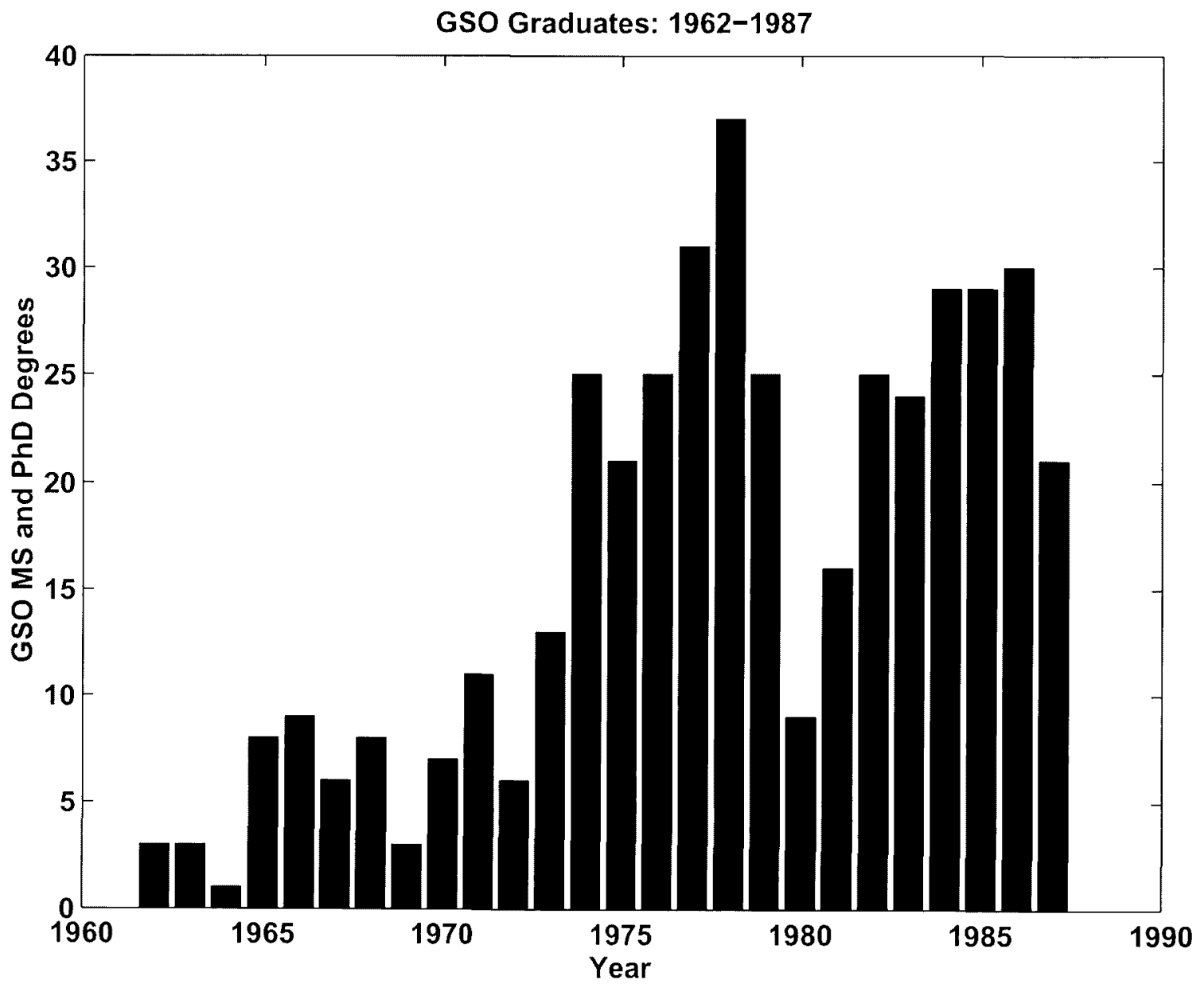

Figure 1. Numbers of degrees granted by the Graduate School of Occanography, University of Rhode Island during the tenure of John A. Knatuss as Dean. 
core courses" approach; often stated another way as "breadth versus depth" (e.g. Sharp, 1995).

I believe that a most important contributing factor to that debate is the tremendous expansion of knowledge during the past forty years about oceanic processes and the interactions of the oceans with the land, atmosphere, and with modern civilization. Of course this phenomenon of the significant expansion of knowledge is not limited to ocean sciences. When faced with even more knowledge to convey to the graduate student, professors of specific areas of ocean science study often argue that the requisite knowledge from other areas of oceanography can be obtained by "reading" because there is so much knowledge that only a series of indepth courses in an area of specialization can provide the requisite education.

Joe Pedlosky in an article about "Graduate Education in Physical Oceanography" acknowledges the influence of Sverdrup, Johnson and Fleming's The Oceans in setting pattern of graduate education in ocean sciences that "philosophically follows in the pattern of the great ocean treatise" in which "All branches of oceanography, i.e. physical, chemical, biological, and geological, are seen as closely fitting parts of a single science. The task of education in this traditional view is to make sure each student knows something about all branches of oceanography" (Pedlosky, 1992). He further states that he thinks that there are serious problems with this attitude, at least with respect to graduate education in physical oceanography. To emphasize his point, Pedlosky notes that Sverdrup, Johnson and Fleming state: "In the field of physical oceanography, the greater part of the theoretical and practical work can be conducted with little or no attention to results in the other marine sciences." Pedlosky then presents a case that favors the definition of breadth for physical oceanography graduate students as breadth in meteorology, mathematics, engineering, and advanced topics in other branches of physics.

No matter what the definition of breadth, I suspect that there appears to be a tendency to sacrifice breadth of knowledge for depth of knowledge in a specialized aspect of ocean sciences. Is there a trend towards specialization within ocean sciences? Is this a natural consequence of maturing of this field of scholarly endeavor? While several of us may have our suspicions that this is or is not happening, I know of no systematic survey or assessment across the field of oceanography that would inform an answer to these questions. We should undertake such an assessment involving faculty, alumni and alumnae of graduate programs in oceanography, current students, and colleagues in disciplines outside of oceanography and marine sciences.
Another challenge that has been with us since at least the late 1960s, has been the issue of interdisciplinary or multidisciplinary studies. Often I hear from graduate students that there are barriers to interdisciplinary research. While I admit that my personal experience may not be the norm, I have found it relatively easy in my career to conduct interdisciplinary research or participate in multidisciplinary research. Perhaps this is because of my participation while a GSO graduate student in a onesemester course with the title Estuaries and organized by Professor Nelson Marshall. I believe the year was 1970. The course was mainly for advanced graduate students who had passed their exams and completed their major course work. The seminar was focused on Narragansett Bay. Lectures included physical oceanography, chemical oceanography, biological oceanography, geological processes, ecological modeling, resource economics, law, and policy. This course had a profound impact on my career. I have never thought I was an "expert" in any of the many fields of study involved in this course. Nevertheless, I have always felt comfortable speaking with scholars and practitioners in those fields because I had been introduced to their language and to their paradigms. In this respect, as well as many others, I believe that GSO was pioneering in graduate education in ocean sciences. John Knauss nurtured this type of learning environment.

\section{Expansion of faculty in oceanography and marine sciences in the United States - a goal that has been achieved}

As mentioned previously, it is my understanding from reading and from discussions with leaders of oceanography that the main intent of graduate education for the Ph.D. during these times of the 1960s and 1970s was focused on educating and training students to fill the research university faculty role in oceanography. In the late 1960s and early 1970s there were only about a dozen colleges and universities offering a Ph.D. graduate education program inclusive of studies for the degree in all of the four major sub disciplines; physical, chemical, geological and biological oceanography. There were several excellent programs offering mainly a degree in marine biology and biological oceanography. My recent check of the Peterson's Guide (Petersons.com, 2001) on the world wide web finds that at present there are thirty nine graduate programs listed in the United States when you search for graduate study in "oceanography" and forty three programs listed when you search for graduate study in "marine sciences". The recent Consortium for Oceanographic 
PhD Degrees Awarded $(n=164)$ 1997-1998 (21 schools)

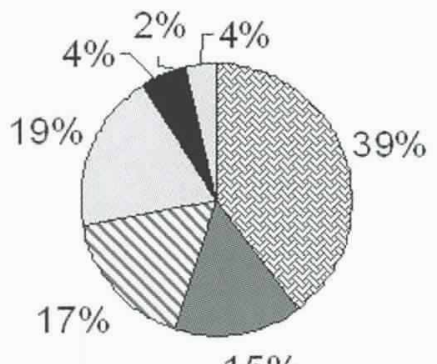

$15 \%$

PhD Degrees Awarded ( $n=156)$ 1998-1999 (21 schools)

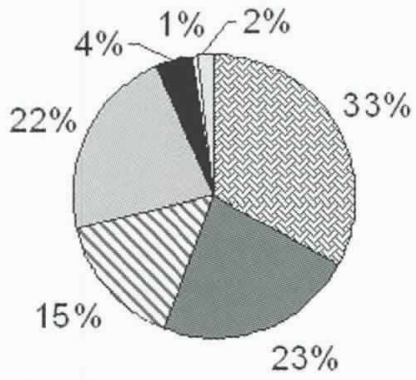

PhD Degrees Awarded $(n=160)$ 1999-2000 (21 schools)

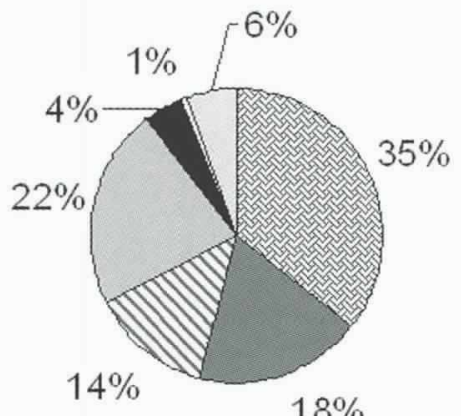

$18 \%$
Masters Degrees Awar ded $(n=120)$

1997-1998 (21 schools)

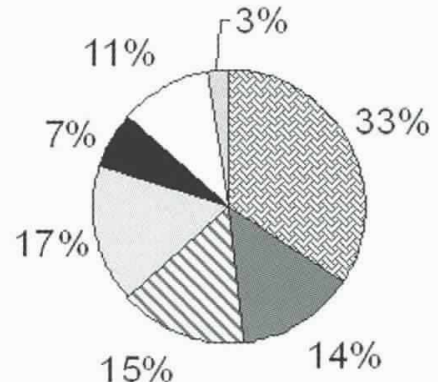

Masters Degrees Awarded ( $n=107)$

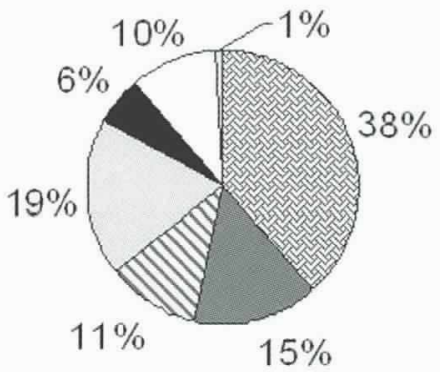

Masters Degrees Awarded $(n=105)$ 1999-2000 (21 schools)

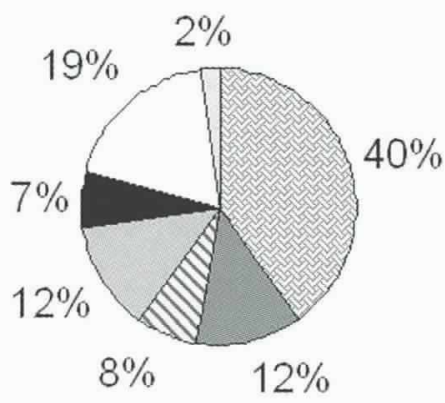
중 Biol.
Chem.
$\triangle M G \& G$
Phys.
Ocean Engg. $\square$ Marine Policy
Other

Figure 2. Numbers of Ph.D. degrees (left column) and M.S. degrees (right column) granted by thirty-six graduate programs reporting to the Ocean Science Educators Retreat Report 2000 Survey of the Consortium for Oceanographic Research and Education, Washington, DC.

Research and Education, 2000 Ocean Science Educators Retreat (OSER) Draft Data Report (personal communication) for graduate education involved surveys received from thirty-six colleges, universities or institutions. Recent numbers of Ph.D. degrees and M. S. degrees granted collectively are presented in Figure 2 taken from that report. In depth interpretation of these and other data of the OSER report is beyond the scope of this paper and should be the subject of an in depth paper in Oceanography in the near future.

I have not systematically checked the credentials of all the faculty of these programs. However, personal knowledge suggests to me that several are graduates of those dozen or so programs of graduate study that were in place or expanding in the late 1960s and early 1970s. Irrespective of the school from which the faculty earned their doctorate degree, it is clear that the desired expansion of graduate education in oceanography sought in the late 1960 s and early 1970s has taken place.

Even though the expansion of faculty was the focus, and has continued to be the focus until the late 1980s and early 1990s, many of the graduates of these 
programs of study pursued other careers. According to data assembled from federal reports by Nowell (2000), nationwide the employment sector for those who earned graduate degrees in oceanography during this time period can be summarized as follows: Industry $10 \%$, Government $14 \%$, Academic Sector $60 \%$, Other $16 \%$. In comparison with most other major fields of science and engineering, more of those who have completed graduate education (mainly the Ph.D.) in oceanography or ocean sciences are in the academic sector.

Thinking about this and the intent of the past expansion of graduate education in ocean sciences, this should not be a major surprise. In most respects it has been a major success story. However, the initial objectives of the late 1960s and 1970s of expanding significantly the professorate and the numbers of scholarly researchers have been met.

\section{The future of graduate education in oceanography}

What are the current objectives of graduate education in ocean sciences in the United States? It is true that the entire enterprise of graduate education in all of the sciences has been under general review at national and university levels for almost a decade (e.g. NAS, 1995; Kelly, 2000). I strongly recommend that ocean sciences and ocean engineering subscribe to the philosophy that first and foremost the objective of a Ph.D. education should be to prepare scientists and engineers " to continue the expansion of fundamental knowledge and to make that knowledge useful to the world" (NAS, 1995). However, the context within which we achieve this fundamental objective, and the value added aspects such as preparation for diverse, rich and rewarding careers for the graduates, need to be reviewed periodically with the intent that our curriculum and framework of graduate education be refreshed.

Admittedly, reforms in the academy are often very slow. Yet there is a disturbing sense that many, but not all, graduate programs in ocean sciences proceed as if it was business (of the 1970s) as usual - a concern I share with Dean McManus (2001). Correctly, much significant thought, innovation and energy have gone into interfacing the exciting aspects of the oceans with $\mathrm{K}-12$ learning about natural processes and natural laws (e.g. Watkins, 1995). In addition, there has been considerable thought, innovation, debate, and energy put into undergraduate learning in the ocean sciences. While graduate education in ocean sciences has not been neglected entirely, I submit that we should be more attentive to the evolution of the learning environment for graduate students in ocean sciences.

At present there is a renewed emphasis for understanding the oceans leading to the call for a Presidential Commission on the Oceans and the evolution of programs such as Global Ocean Observing Systems (GOOS) or Integrated Ocean Observing Systems (IOOS) in the national and international arena.
It is a propitious time for the ocean sciences community to review thoroughly and learn from the evolution of our graduate programs in ocean sciences with the view of offering a better learning environment for present and future master's degree and doctorate degree graduate students and to serve emerging national and international needs. I suggest the following as an initial, but by no means complete, set of questions for this review.

What are our national objectives in ocean sciences graduate education in addition to the general objective cited above for the doctorate education "to continue the expansion of fundamental knowledge and make that knowledge available to the world"(NAS, 1995)?

How best to balance the "breadth versus depth" issue given the explosion of knowledge?

How best to offer ocean sciences graduate education within the context of the interactions with other earth sciences and with physical sciences, biological sciences and social sciences?

How will the evolution of undergraduate education in the sciences influence graduate education in occan sciences?

How to utilize most effectively web-based learning and emerging Internet technologies?

Should we combine in multi-college/university collaborations to maximize effective use of resources?

Is there a role for multi-student interdisciplinary or multidisciplinary dissertations in ocean sciences?

How do we encourage, educate and train future ocean scientists with strengths in ocean observations to ensure ocean measurements that will enable and complement theory and models?

How do we best promote and nurture diversity in all its manifestations within our community of ocean scientists and geosciences in general?

What is the most effective role of graduate programs interacting with developed countries to enhance graduate education in ocean sciences in developing countries?

No matter the answers to the above questions, I commend to you the following general set of values set forth by Arthur R. M. Nowell in his lecture, "Education in Oceanography: History, Purpose, and Prognosis" (Nowell, 2000). 
We strive to teach students the language of ocean sciences and some things of the disciplines that are its underpinnings.

We introduce students to the ways of science that imply familiarity with the tools and methodologies of inquiry and with the conceptual as well as practical problems of ocean sciences.

We help students learn critical thinking skills including the methods of reasoning logically, deductively, inductively, of accuracy and precision and the limitations of data and methods.

We help students become effective communicators and strive to persuade students to teach others.

We inculcate a personal love of learning that will last a lifetime so that internal scholarly standards and a continuing curiosity become the basis for living.

Reflecting on my graduate education at GSO, one of the memorable parts of the education I value highly is that received from other graduate students in the weekly Seminar in Oceanography. I am pleased to note that according to the GSO website this one course, Course 695 , continues as a requirement of all graduate students in residence each semester. Faculty members were "required" to attend, although I suspect that enforcement of this "requirement" has been problematic over the years. I believe strongly that a significant portion of education as a graduate student comes from other graduate students in seminars and informal discussions. This aspect of graduate education should continue and should be nurtured whenever and wherever possible in ocean sciences with a broad focus inclusive of the many sub disciplines of ocean sciences. This is not to downplay the important role of professors as teachers, advisors and mentors. Rather it is to emphasize a part of graduate education often overlooked.

A periodic gathering of graduate students and faculty as a whole to learn from seminars presented by bright enthusiastic graduate students, with topics ranging across all aspects of oceanography and ocean sciences, should be at the heart of a learning environment that partly satisfies at least one of Arthur Nowell's challenges: "inculcate a personal love of learning that will last a lifetime." To honor John Knauss, I dedicate myself to doing my best to launch such a gathering at Woods Hole Oceanographic Institution within the MIT/WHOI Joint Program.

\section{Acknowledgements}

I extend profound and abiding appreciation to John Knauss for his leadership at GSO-URI and in oceanography worldwide. I thank Professor James Yoder, Interim Dean at GSO-URI, and Ms. Deborah Morrisey at GSO-URI for providing the data and plot of graduates of GSO-URI. Kenneth Brink provided valuable comments about the manuscript. This is Contribution Number 10464 of Woods Hole Oceanographic Institution.

\section{REFERENCES}

Baker, D.J., 1992: The Oceans 50th Anniversary. Oceanography, 5, 154-155.

Kelly, E., 1998: The Future of Graduate Education. In: Remarks to the Council of Scientific Society Presidents Truenty-fifth Anniversary by the Chairman of the National Science Board. National Science Foundation, Washington DC December 7, 1998, 7 pp.

McManus, D., 2001: In the Oceanography Classroom: What is the purpose of the Ph.D. Degree Program? Oceanography, 14, 88-89.

NAS, 1995: Reshaping the Graduate Education of Scientists and Engineers. National Academy Press, Washington, DC, $207 \mathrm{pp}$.

Nowell, A.R.M., 2000: Education in Oceanography: History, Purpose, and Prognosis. In: 50 Years of Ocean Discozery National Science Foundation 1950-2000. National Academy Press, Washington, DC, 195-200.

Nowell, A.R.M. and C.D. Hollister, 1988: Graduate Students in Oceanography: Recruitment, Success, and Career Prospects. EOS, 69, 834-835, 840-843.

Pedlosky, J. 1992: Graduate Education in Physical Oceanography. Oceanography, 5, 117-120.

Petersons, 2001: Petersons.com on the World Wide Web. GradChannel Search.

Sharp, J.H., 1995: Diverse Career Possibilities and a Broad Oceanography Curriculum. Oceanograplly, 8, 106-107.

Sverdrup, H.U., M.W. Johnson and R.W. Fleming, 1942: The Oceans: Their Physics, Chemistry and General Biology. Prentice-Hall, Englewood, NJ, 1060 pp.

Watkins, J.D. 1995: Linking Public Policy Support for Ocean Science to Pre-College Education. Oceanography, 8, 103-105. 